\title{
Electrochemical biosensors for pesticide determination in food samples
}

\author{
G.S. Nunes ${ }^{1}$ and D. Barceló ${ }^{2, *}$ \\ ${ }^{1}$ Dept. Technol. Chemistry, Fed. Univ. of Maranhão/UFMA, Av. Portugueses, s/n, 65080-040 São Luís - Ma, Brazil \\ ${ }^{2}$ Dept. Environ. Chem., CID/CSIC, clo Jordi Girona, 18, 08040 Barcelona, Spain
}

\begin{abstract}
An overview of the different electrochemical biosensors for pesticide determination in food matrices is presented. Cholinesterase-based biosensors, for the analysis of carbamate and organophosphorus pesticides have been the most widely used in this specific area of research. Organophosphorus and carbamate pesticide residues are often detected in crop samples, so biosensors can be a god tool for the screening of food products in rotuine control laboratories. The matrix effect and the comparison with chromatographic techniques for validation studies are also discussed. Enzymatic biosensors for other classes of pesticides like dithiocarbamte fungiciodes and various herbicides are summarized.
\end{abstract}

\footnotetext{
$\mathrm{n}$ the last years, the intensive agriculture has highlighted the need of procedures to study the impact of presence of pollutants in crops and foodstuffs. In contrast, most papers that have appeared focusing this theme are attempt to show their applicability in analysis of environmental matrices [1,2]. The current generation of pesticides, such as organophosphate (OP), carbamates and pyretroids, are being determined in several kinds of samples by using chromatographic techniques which are usually more expensive and time-consuming than the biological techniques, and need more sophisticated equipment.
}

Methods based on enzymatic recognizing such as enzyme-linked immunoassay techniques have been developed for a large variety of analytes, varying from natural components to contaminants in food and environmental samples [3]. Also, biosensors able to analyze some natural components and additives in foodstuffs and crop samples have been developed and used to quality control [4,5] and to industrial food processes monitoring [6,7]. Biosensor is an analytical tool which can be defined as a combination of a biological recognition element (as for example enzyme, whole cell, antibody, microbe) and a physical transducer, in intimate contact with each other. The role of the transducer is to relate the concentration of an analyte into a chemical and/or physical property, which is sequentially sensed, converted into an electrical/optical signal and amplified [8-11]. Many transduction principles are available, including photometry, fluorimetry and chemiluminescence, fiber optics, piezoelectric sensing, potentiometric and amperometric electrodes.

Despite their apparent potential as analytical tools in food analysis, only a few biosensors are used routinely. Moreover, although improvements of the enzyme immobilization techniques for electrode construction have substantially contributed to detection of several contaminants at trace levels, the application of the electrochemical biosensors for the determination of pesticides in food samples has only increased slowly. Analytical methods employing enzyme sensors based on the inhibition of cholinesterase with potentiometric or amperometric detection have been developed for the determination of organophosphate and carbamate insecticides [12]. Despite the high sensitivity and reproducibility of some ChE-based sensors, the development of methods employing biosensors to pesticide residues monitoring in food samples is still limited. This paper provides a rapid discussion about the electrochemical approaches which have been developed for the determination of pesticide in food samples.

\section{Cholinesterase-based biosensors for the analysis of organophosphorus and carbamate insecticides}

Generally, the enzyme electrodes constructed to pesticide analysis have been based on the cholinesterase (ChE) enzymes immobilized of different modes. There are two basic types of cholinesterases: acetylcholinesterase (AChE) and butyrylcholinesterase (BChE). Crystal structures of the AChEs were elucidated [13,14], and the mode of action of this class of enzymes in living organisms has been described in the literature $[15,16]$. AChE enzymes catalyze the hydrolysis of the natural substrate acetylcholine, and such reaction can be monitored electrolytically:

$$
\begin{aligned}
& \text { Acethylcholine }+\mathrm{H}_{2} \mathrm{O} \stackrel{\mathrm{AChE}}{\longrightarrow} \text { Choline }+ \text { Acetic acid } \\
& \text { 2Choline } \stackrel{\text { anodic oxidation }}{\longrightarrow} 2 \text { Choline }+2 \mathrm{H}^{+}+2 \mathrm{e}^{-}
\end{aligned}
$$

ChE enzymes are commercially available with very high stability and sensitivity and their activity can be measured using potentiometric or amperometric transducers. These kind of enzymes are inhibited by both organophosphorus (e.g., malathion, parathion and paraoxon) and carbamate insecticides (e.g., aldicarb, carbaryl and propoxur), but

* To whom correspondence should be addressed. 
depending of the pesticide class, the mechanism of inhibition can be different. In case of the reaction with carbamates, for example, the carbamylated enzyme is slowly hydrolyzed spontaneously, so that the inhibition is partially reversible [12].

Despite their low mammalian toxicity and relative low persistence in the environment, a suitable control of ChEinhibitor residues is need. For a long time, $\mathrm{pH}$ sensors were used for monitoring the amount of acetic or butyric acid formed during hydrolysis of acetyl- or butyrylcholine, which is proportional to the enzymatic activity. Several enzyme immobilization techniques, including the use of crosslinking with glutaraldehyde and albumine [17,18], activated acrylamide-based prepolymers [19], covalent immobilization on preactivated polyamide membrane [20], and glass beads coated with AChE [21] were used. Some approaches using salts of acetyl- or butyryl(thio)choline (most commonly iodide) as substrates have been proposed. In this case, after enzyme inhibition, less thiocholine is produced, being the potential then determined by the $I^{-} / I_{2}$ par [22].

With amperometric transducers, two types of biosensors can be constructed. One possibility is based on choline oxidase (ChOD) that catalyzes the oxidation of choline produced, according reaction below:

CholCholine $+2 \mathrm{O}_{2}+\mathrm{H}_{2} \mathrm{O} \stackrel{\text { ChOD }}{\longrightarrow}$ Choline acetate $+2 \mathrm{H}_{2} \mathrm{O}_{2}$.

The consumption of oxygen could be measured using a Clark oxygen electrode, but more sensitive methods employ platinum electrodes for monitoring the production of hydrogen peroxide were described [12]. Both $\mathrm{ChOD}$ and $\mathrm{ChE}$ could be coimmobilized in the same PVA layer prepared either on a supporting membrane [23], or on a surface of a carbon fiber [24], but coimmobilization was also performed in gelatine [25] and acetylcellulose layers [26,27].

The second alternative is by using only ChE enzymes, and in this case acethylthiocholine iodide has been preferred as substrate. As suitable electrodes, either platinum, graphite or graphite epoxy composite with entrapped ChEs were reported [28-30]. The composites based on carbon paste modified with cobalt (II) phytalocyanine have been prepared by print screen techniques and have shown to be reproducible and sensitive [31,32].

Anticholinesterase compounds have been determined in a few food matrices, and here we will include drinking waters as a food category $[33,34]$. Table I summarizes some applications for the ChE-based biosensors in food analysis. La Rosa et al. [35] detected the presence of some ChEinhibitors in samples of fruits and vegetables by employing an amperometric biosensor and measuring the relative inhibition caused by organophosphorus. Since the determination of polar compounds in vegetable matrices is often accompanied of previous extraction/clean up procedures, and consequently the final extract must be obtained by dissolution of the pesticide residues in organic solvents, Mionetto et al. [36] studied the effect of different solvents on the ChE activity. They observed that the stability of free AChE strongly decreased in all water-miscible solvents (methanol, ethanol, acetonitrile, butanol), whereas with immobilized enzymes this effect was less pronounced, specially after incubation of the enzyme with acetonitrile and butanol. Recently, Garcia and Marty [37] modified chemically the AChE (from elec- tric eel) with methoxypolyethylene glycol (mPEG) in order to increase the tolerance of the enzyme to organic solvents. The authors noticed that with this procedure the enzymatic activity was preserved but, in contrast, enzyme thermostability decreased. Skládal et al. [38] applied the well-known methodology optimized by De Kok [39] for the determination of $\mathrm{N}$-methylcarbamate (NMC) insecticides in some crop samples and found a good correlation between biosensor and LC analysis of carbofuran in samples of potatoes without no sample pretreatment. Also, Nunes et al. [40] used CoPCmodified sensors containing immobilized ChEs to screening NMCs in untreated crop samples. The biosensor method was favorably compared to a HPLC method. The authors observed that the for most NMCs, the inhibition curves have exhibited a sigmoidal shape as showed in figure 1. For this reason, the pesticide recoveries calculated from linear curves were lower when compared with those obtained from sigmoidal inhibition curves.

\section{Analysis of other classes of pesticides}

Other classes of pesticides have also been determined by different electrochemical approaches. For example, several photosynthetic cyanobacteria-based sensors were developed by Rawson et al. [41] for the detection of a wide range of herbicides with sites of action on the photosynthetic electron transport chain. Purcell and Carpentier [42] constructed a biosensor based on immobilized thylakoids in order to measure the perturbation of photosynthetic activity by anodic oxidation of hydrogen peroxide. Wiegand-Rosinus et al. [43] demonstrated that the dithiocarbamate fungicides act in living organisms by inhibiting the aldehyde dehydrogenase enzymes which are involved in the biosynthesis of the branched amino-acids valine, leucine and isoleucine. With amperometric biosensors, the decreased current signal can be monitored and the relative inhibition measured [44]. In the same mode, sulfonylurea herbicides can be detected at trace levels through inhibition of the enzyme acetolactase synthase [45]. Detection and sensitivity tests have been

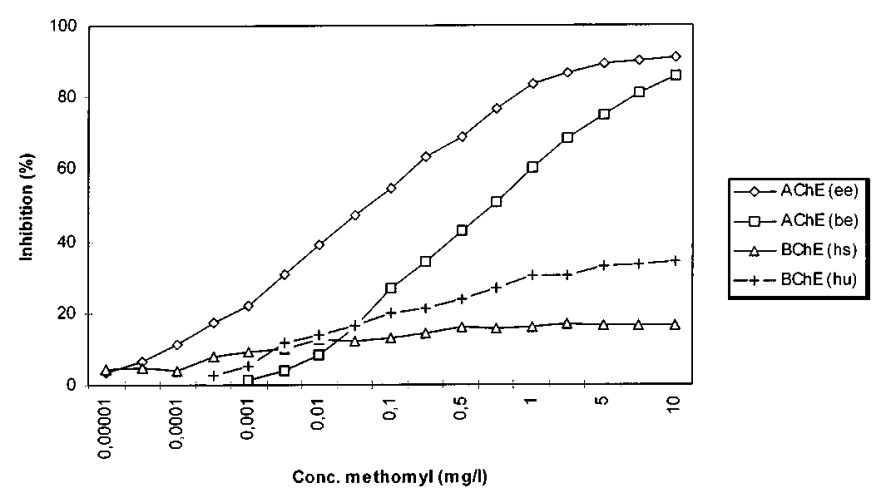

Figure 1. Calibration curve for methomyl constructed by using ChE-based amperometric biosensros. AChE - Acetylcholinesterase from electric eel (ee) and bovine erythrocyte (be); BChE - butyrylcholinesterase from horse serum (hs) and human serum (hu). Modifier: CoPC; Substrate: acethylthiocholine iodide; Applied potential: + $0.35 \mathrm{~V}$ vs. Ag/Agl. (from Ref. [40]). 
Table I. Some Amperometric biosensors used for the determination of pesticide residues in food matrices.

\begin{tabular}{|c|c|c|}
\hline Electrode System & Analyte & Ref. \\
\hline $\begin{array}{l}\text { Platinum working electrode containing ChE enzymes. Reference electrode: } \\
\mathrm{Ag} / \mathrm{AgCl}\end{array}$ & $\begin{array}{l}\text { Organophosphorus and } \\
\text { carbamate insecticides }\end{array}$ & 35 \\
\hline $\begin{array}{l}\text { Platinum electrode containing } \mathrm{ChE} \text { within photocrosslinkable PVA-SbQ (8\%). } \\
\text { Reference electrode: } \mathrm{Ag} / \mathrm{AgCl}\end{array}$ & $\begin{array}{l}\text { Organophosphorus and } \\
\text { carbamate insecticides }\end{array}$ & 36 \\
\hline $\begin{array}{l}\text { CoPC-modified graphite ChE-based electrodes (sensor base prepared by print } \\
\text { screen techniques). Reference electrode: } \mathrm{Ag} / \mathrm{Agl}\end{array}$ & Carbamate insecticides & 38 \\
\hline $\begin{array}{l}\text { CoPC-modified graphite ChE-based electrodes (sensor base prepared by print } \\
\text { screen techniques). Reference electrode: } \mathrm{Ag} / \mathrm{Agl}\end{array}$ & Carbamate insecticides & 40 \\
\hline $\mathrm{Fe}(\mathrm{CN})_{6}^{3 / 4-}$-modified photosynthetic cyanobacteria-based electrodes & Herbicides & 41 \\
\hline $\mathrm{H}_{2} \mathrm{O}_{2}$-based electrodes containing immobilized thyklakoids & Herbicides & 42 \\
\hline Adehyde dehydrogenase-based electrodes & Dithiocarbamate fungicides & 43 \\
\hline Hexacyanoferrate(III) modified aldehyde dehydrogenase-based electrodes & Dithiocarbamate fungicides & 44 \\
\hline
\end{tabular}

carried out with such systems, but the assays have been still performed with standard solutions.

\section{Conclusions and future trends in pesticide detection}

Several electrochemical approaches developed for the analysis of pesticides in food matrices were discussed in this overview. Thus, biosensors based on cholinesterases, aldehyde dehydrogenases and acetolactase synthase, used for the detection of organophosphorus/carbamate, dithiocarbamate and sulfonylurea pesticides, respectively, were presented.

Different immobilization techniques for construction of the sensors were developed in the last twenty years, but we can observe that the use of mediated electrodes is today an exigency in this field, since the reliability of the measurements is undoubtedly higher if the electron transfer is of some mode favored.

Biosensor determination of contaminants, such as pesticides, in non-aqueous media have also been performed through of modifications in the enzyme structures. Thus, the determinations of low concentration residues of pesticides have been performed in presence of organic solvents, but improvements are still necessary in order to overcome the problem of interferences present in real samples. On the other hand, analytical methodologies based on direct amperometric detection of some contaminants in food and crop samples have been developed and favorably compared to well-established analytical methods. Although with careful electrode preparation direct enzymatic reaction in presence of real samples had been achieved, new strategies for sample interference minimization must be investigated.

With the advances in biosensor technology, in a near future reliable systems for food analysis based on biological recognition elements combined with suitable polymers will be available. Such systems will allow both diffusion of the substrates and rapid electron transfer, and then will be possible to fashion suitable sensors that are more sensitive, yet robust; inexpensive, yet selective. But there is still a long way to go through, and a feedback of improvements and new applications are very important in order to further develop this tool for food quality control.

\section{Acknowledgements}

This work was supported by the Commission of the European Communities Environmental Program, RIANA Contract Number ENV4-CT95-0066 and CICYT Contract Number AMB96-2808-CE. G. S. Nunes would like thank $\mathrm{CNPq}$, a Brazilian research agency for fellowship.

\section{References}

1. Marco, M.-P.; Barceló, D. Meas. Sci. Technol. 1996, 7, 1547.

2. Krämer, P. M. J. Assoc. Off. Anal. Chem. 1996, 79, 1245.

3. Nunes, G. S.; Toscano, I. A.; Barceló, D. Trends Anal. Chem. 1998, $17,79$.

4. Maines, A.; Ashworth, D.; Vadgama, P. Food Technol. And Biotechnol. 1996, 34, 31.

5. Campanella, L.; Tomassetti, M. Food Technol. Biotechnol. 1996, 34, 131.

6. Luong, J. H. T.; Groom, C. A.; Male, K. B; Biosensors Bioelectronics 1991, 6, 547.

7. Deshpande, S. S.; Rocco, R. M. Food Technol. 1994, 8, 146.

8. Datta, A. K. J. Food Eng. 1990, 12, 223.

9. Richter, E. R. J. Dairy Sci. 1993, 76, 3114.

10. Buerk, D. G. Biosensors: Theory and Applications, Technomic Publishing, Basel, Switzerland, 1993.

11. Kress-Rogers, E. Biosensors and Electronic Noises, Boca Raton, CRC Press, Florida, USA, 1997; p 695.

12. Skládal, P. Food Technol. Biotechnol. 1996, 34, 43. 
13. Sussman, J. L.; Harel, M.; Frolow, F.; Oefner, C.; Goldman, A.; Toker, L.; Silman, I. Science 1991, 253, 872.

14. Harel, M.; Kleywegt, G.; Ravelli, R. B. G.; Silman, I.; Sussman, J. L. Structure 1995, 3, 1355.

15. Froed, H. C.; Wilson, I. B. Acetylcholinesterase. In: The Enzymes, Boyer, P. D. Ed., Academic Press, New York, 1971; pp 87-97.

16. De Jong, L. P. A.; Gross, C. C.; Van Dijk, C. Biochim. Biophys. Acta 1971, 227, 475.

17. Tran-Minh, C.; Guyonnet, R.; Beux, J. Comp. Rend. 1978, 286, 115.

18. Kumaran, S.; Meier, H.; Danna, A. M.; Tran-Minh, C. Anal. Chem. 1991, 63, 1914.

19. Tran-Minh, C.; Pandey, P. C.; Kumaran, S; Biosensors Bioelectronics 1990, 5, 461.

20. Kumaran, S.; Tran-Minh, C. Electroanalysis 1992, 4, 949.

21. Kumaran, S.; Tran-Minh, C. Anal. Biochem. 1992, 200, 187.

22. Guilbault, G. G. Analytical uses of immobilized enzymes, Dekker M. Ed., New York, 1984; p 342.

23. Marty, J. -L.; Sode, K.; Karube, I. Anal. Chim. Acta 1989, 228, 49.

24. Navera, E. N.; Sode, K.; Tamiya, E.; Karube, I. Biosensors Bioelectronics 1991, 6, 751.

25. Wollenberger, U.; Setz, K.; Scheller, F.; Löffler, U.; Göpel, W.; Gruss, R. Sensors Actuators B 1991, 4, 257.

26. Campanella, L.; Achilli, M.; Sammartino, M. P.; Tomasseti, M. Bioelectrochem. Bioenerg. 1991, 26, 237.

27. Bernabei, M.; Cremisini, C.; Mascini, M.; Palleschi, G. Anal. Lett. 1991, 24, 1317.
28. Gruss, R.; Scheller, F.; Shao, M. J.; Liu, C. C. Anal. Lett. 1989, 22, 1159.

29. Stoytcheva, M. Electroanalysis 1995, 7, 560.

30. Martorell, M.; Céspedes, F.; Martinez-Frabegas, E.; Alegret, S. Anal. Chim. Acta 1994, 290, 343.

31. Skládal, P. Anal. Chim. Acta 1991, 252, 11.

32. Kulys, J.; D'Costa, E. J. Biosensors Bioelectronics 1991, 6 , 109.

33. Salamoun, J.; Remien, J. Int. J. Environ. Anal. Chem. 1994, 57, 163.

34. Günther, A.; Bilitewski, U. Anal. Chim. Acta 1995, 300, 117.

35. La Rosa, C.; Pariente, F.; Hernandez, L.; Lorenzo, E. Anal. Chim. Acta 1995, 308, 129.

36. Mionetto, N.; Marty, J.-L.; Karube, I. Biosensors Bioelectronics 1994, 9, 463.

37. Garcia, D.; Marty, J. -L. Appl. Biochem. Biotechnol. 1997, 67, 153.

38. Skladal, P.; Nunes, G. S.; Yamanaka, H.; Ribeiro, M. L. Electroanalysis 1997, 9, 1083.

39. De Kok,A.; Hiemstra, M.; Vreeker, C. P. J. Chromatogr. 1987, 24, 469.

40. Nunes, G. S.; Skládal, P.; Yamanaka, H.; Barceló, D. Anal. Chim. Acta 1998, 795, 43.

41. Rawson, D. M.; Willmer, A. J. Biosensors 1989, 4, 299.

42. Purcell, M.; Carpentier, R. Water Poll. Res. J. Canada 1990, $25,175$.

43. Wiegand-Rosinus, M.; Obst, U.; Haberer, K.; Wild, A. Environ. Toxicol. Wat. Quality 1992, 7, 313.

44. Noguer, T.; Marty, J. -L. Anal. Chim. Acta 1997, 347, 63.

45. Chaleff, R. S.; Mauvais, C. J. Science 1984, 224, 1443. 